\title{
Simulation of Water Circulation over a Model of a Submarine Canyon by Using FIC-FEM Numerical Model
}

\author{
A. German ${ }^{1}$; J. García-Espinosa²; M. Espino ${ }^{3}$; and M. A. Maidana ${ }^{4}$
}

\begin{abstract}
A set of numerical model experiments has been conducted to simulate the circulation driven by oscillatory forcing over a theoretical continental slope configuration used previously in laboratory experiments. The test case considered was the numerical simulation of the flow over a model of a submarine canyon, and the numerical model used in the analysis was a coastal ocean model version based on an adaptation of the finite-calculus-finite-element method (FIC-FEM) approach implemented in the commercial package Tdyn. Two cases were analyzed involving changes in fluid density. Structured and unstructured finite-element spatial discretizations were generated for the same study domain to compare the resulting velocity field with outputs from the laboratory experiments and to assess which mesh provided a better representation of the complex geometry of the channel model and the water circulation process. The comparison between the laboratory results from the reference article and the output of the numerical model showed good agreement in the structure and magnitude of the phaseaveraged and residual velocity fields.
\end{abstract}

Author keywords: Submarine canyon; Coastal flow; Tdyn; Finite element; FIC.

\section{Introduction}

The continental shelf is a transition zone between the coastline and the open sea, and is interrupted at irregular intervals by submarine canyons that are present on the shelf edge along most of the world's coastlines. Coastal canyons have long been of interest to scientists because of their geological and biological importance. Physical oceanographers find evidence that these topographic features are preferred pathways for shelf-slope transport of material and energy and play important roles in distributing suspended particulate matters and exporting sediments to the open ocean (Durrieu de Madron 1994). From a biological point of view, enhanced species diversity and biological productivity can be found in submarine canyons. Sardà et al (1994) find evidence that these regions are preferential recruitment habitats, whereas Gili et al. (2000) see canyons as biodiversity hot spots.

Studies on the effects of canyon topography on the regional circulation are relatively few; they have been reviewed by Hickey (1995) and Huthnance (1995). Field observations are very rare

${ }^{1}$ Researcher, International Center for Numerical Methods in Engineering, Universitat Politècnica de Catalunya, Edifici C1, Campus Nord, Gran Capitá, s/n 08034 Barcelona, Spain (corresponding author). E-mail: arnel .german@upc.edu

${ }^{2}$ Researcher, International Center for Numerical Methods in Engineering, Universitat Politècnica de Catalunya, Edifici C1, Campus Nord, Gran Capitá, s/n 08034 Barcelona, Spain. E-mail: julio@cimne.upc.edu

${ }^{3}$ Associate Professor/Lecturer, Laboratori d'Enginyeria Marítima, Universitat Politècnica de Catalunya, Edifici D1 Campus Nord, Gran Capità s/n 08034. E-mail: manuel.espino@upc.edu

${ }^{4}$ Researcher, International Center for Numerical Methods in Engineering, Universitat Politècnica de Catalunya, Edifici C1, Campus Nord, Gran Capitá, s/n 08034 Barcelona, Spain. E-mail: augusto.maidana@upc.edu

Note. This manuscript was submitted on February 20, 2010; approved on May 24, 2011; published online on May 26, 2011. Discussion period open until June 1, 2012; separate discussions must be submitted for individual papers. This paper is part of the Journal of Waterway, Port, Coastal, and Ocean Engineering, Vol. 138, No. 1, January 1, 2012. (CASCE, ISSN 0733-950X/2012/1-0-0/\$25.00. [e.g., Hickey (1997) and Bosley et al. (2004)] because physical measurements in submarine canyons are among the most complicated to make. Various factors contribute to the difficulty of performing field measurements including the steepness of canyon slopes and the maintenance of the moored arrays of conductivitytemperature-depth (CTD) sensors in water because of intense fishing activities concentrated in these areas. These few field studies helped explain some previously unknown processes, but also presented shortcomings that include high cost and the difficulty of attributing a specific cause to an observed effect because of the simultaneous occurrence of many physical processes. More recently, the focus of attention has been the use of numerical experiments to address these drawbacks. Several numerical experiments relating to submarine canyons have been conducted and have shown that circulation within the submarine canyons is characterized by both downwelling and upwelling events. Some numerical models (Hurlburt 1974; Peffley and O'Brien 1976) have demonstrated that canyons affect the patterns of regional upwelling and that upwelling is enhanced on the downstream side of a canyon. Klinck (1988) attempted to model the circulation in a submarine canyon and its interaction with shelf flow using a vertically walled channel, providing the first insight into canyon-flow interaction. His studies showed that the width of the canyon is an important parameter, and the interaction was found to be smaller for canyon widths smaller than the current width or the internal Rossby radius of deformation (ratio between the phase speeds of the long internal waves to the Coriolis parameter). Two models (Allen 1996; Klinck 1996) with realistically steep and abrupt topography provided major contributions to the understanding of the interaction of shelf flow with coastal canyons. The outputs from these models were qualitatively consistent with the set of spatially comprehensive observations available. Several attempts to use numerical modeling to simulate current circulation followed, and Haidvogel and Beckman (1995) conducted an intermodel comparison.

Numerical models, supported by adequate field data, provide increasingly realistic results that can be used to predict general flow patterns, but the absence of suitable validation tools leaves the issue 
of using numerical models with a few doubts. As an alternative, recently formulated numerical models have relied on comparisons with the outputs of other numerical and laboratory models for validation purposes even though comparisons between numerical models have been proven inconclusive.

In this paper, the effects of sea floor topography, particularly the presence of submarine canyons, on water circulation were analyzed through a theoretical continental slope configuration used previously in laboratory experiments. The plan was to compare the outputs of the numerical model used in the analysis with the results obtained from the laboratory experiment (Pérenne et al. 2001).

\section{Description of the Numerical Model}

The numerical model employed is a coastal ocean model version based on an adaptation of the finite-calculus-finite-element method (FIC-FEM) (Oñate and García-Espinosa 2001; García-Espinosa and Oñate 2003; Oñate et al. 2006) implemented in the commercial package Tdyn. The stabilized governing equations for the incompressible fluid and the free surface were derived by the use of a finite-calculus (FIC) procedure, which is a technique based on writing the different balance equations over a domain of finite size and retaining the higher order terms. The resulting stabilized numerical solution scheme, coupled with the use of finite-element discretization of the domain, allowed the numerical model greater flexibility, especially when dealing with the complex geometry of irregular coastlines and seabeds.

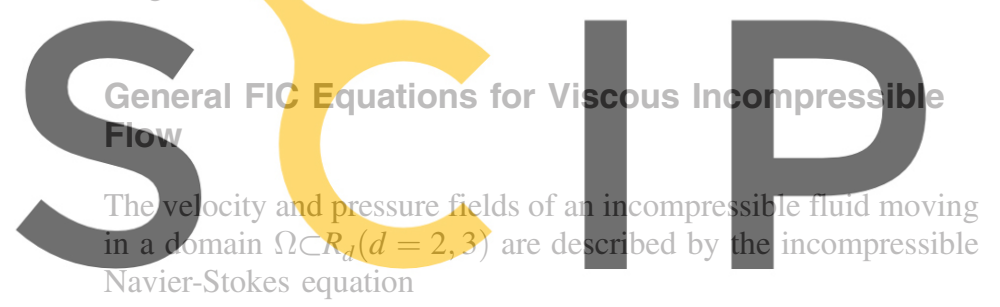

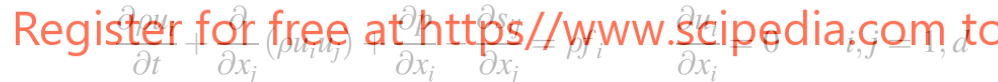

where $1 \leq i ; j \leq d ; \rho=$ density of the fluid; $u_{i}=i$ component of the velocity field $\mathbf{u}$ in the global reference $x_{i} ; p=$ pressure field; and $s_{i j}=$ viscous stress tensor defined by

$$
s_{i j}=2 v\left(\varepsilon_{i j}-\frac{1}{3} \frac{\partial u_{k}}{\partial x_{k}} \delta_{i j}\right) \quad \varepsilon_{i j}=\frac{1}{2}\left(\frac{\partial u_{i}}{\partial x_{j}}+\frac{\partial u_{j}}{\partial x_{i}}\right)
$$

The stabilized FIC form of the governing differential equations in Eq. (1) can be written as

$$
r_{m_{i}}-\frac{1}{2} h_{i j}^{m} \frac{\partial r_{m_{i}}}{\partial x_{j}}=0 \quad \text { in } \Omega
$$

for momentum and

$$
r_{d}-\frac{1}{2} h_{j}^{d} \frac{\partial r_{d}}{\partial x_{j}}=0 \quad \text { in } \Omega
$$

for mass balance. The terms $r_{m_{i}}$ and $r_{d}$ are the residuals of Eq. (1) and $h_{i j}^{m}$ and $h_{j}^{d}$ are the characteristic lengths that represent the dimensions of the finite domain in which the mass balance and the momentum are imposed. The details of the FIC method for the computation of the stabilization terms can be found in Oñate (1998).
The boundary conditions for the stabilized problem correspond to the following equations:

$$
n_{j} \sigma_{i j}-t_{i}+\frac{1}{2} h_{j} n_{j} r_{m_{i}}=0 \quad \text { on } \Gamma_{t} \quad u_{j}=u_{j}^{p} \quad \text { on } \Gamma_{u}
$$

where $n_{j}=$ vector component normal to the boundary; $t_{i}$ and $u_{j}^{p}=$ prescribed surface tractions and velocity; $\Gamma_{t}$ and $\Gamma_{u}=$ two sets of disjoint components of the boundary $\partial \Omega$ where the Neumann and Dirichlet boundary conditions for the velocity are prescribed; and $\sigma_{i j}=$ total stress defined as

$$
\sigma_{i j}=s_{i j}-p \delta_{i j}
$$

Eqs. (3)-(5) are the starting points in the derivation of the stabilized finite-element method (FEM) to solve the incompressible NavierStokes equations. The equations are multiplied by generic weighting functions and the resulting weighted momentum and mass balance equations are integrated over the domain using the finiteelement method (García-Espinosa et al. 2008).

An interesting feature of the FIC formulation is that it allows the use of equal order interpolation for the velocity and pressure variables (Oñate et al. 2004).

\section{Physical Model Geometry}

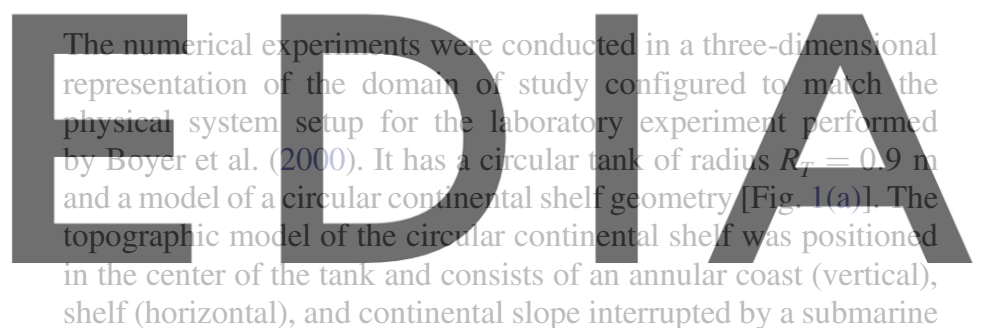

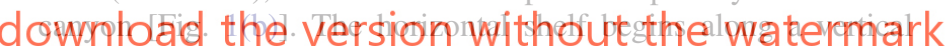

coastline of radius $R_{C}$ and the shelf break is located at radius $R_{S}$ The canyon incises both the continental shelf and the offshore slope. Its length is $2 L$, measured along the axis from the point at which it intersects the horizontal shelf to the radius at which the sloping region reaches the deepwater floor. Its characteristic width $W$ is the distance along the shelf break between the points at which the canyon intersects the shelf. The deep ocean is the part between the continental slope and the outside wall of the test cell.

The tank was filled with fluid, and both homogenous and linearly stratified density situations were considered. The objective was to find the effect of fluid density-aside from the presence of a submarine canyon-on circulation. The system was made to rotate and the mean rotation of the turntable was not varied during the experiment. The background rotation of the tank was set at a constant Coriolis parameter of $f=0.5 \mathrm{~s}^{-1}$, and the simulated oceanlike flow was the along-isobath oscillatory flow defined as

$$
v_{\theta}=-u_{0} \frac{r}{R_{s}} \sin \left(\omega_{0} t\right)
$$

where $\mathbf{u}_{\mathbf{0}}=1 \mathrm{~cm} \mathrm{~s}^{-1}$ is the amplitude of the velocity at the shelf break, which is located at $r=R_{S} ; \omega_{0}=$ oscillation frequency; and $t=$ time. The rotation was modulated sinusoidally to establish an oscillatory, along-shelf, background motion relative to an observer fixed to the canyon. Table 1 contains the values of the dimensional parameters. 


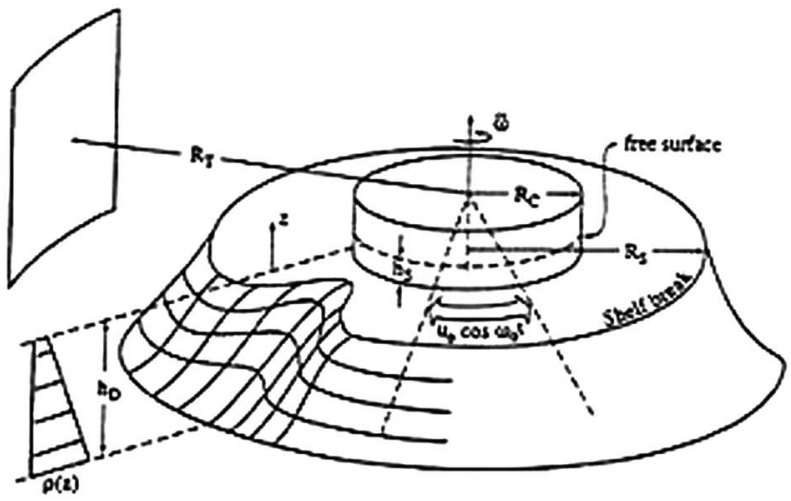

(a)

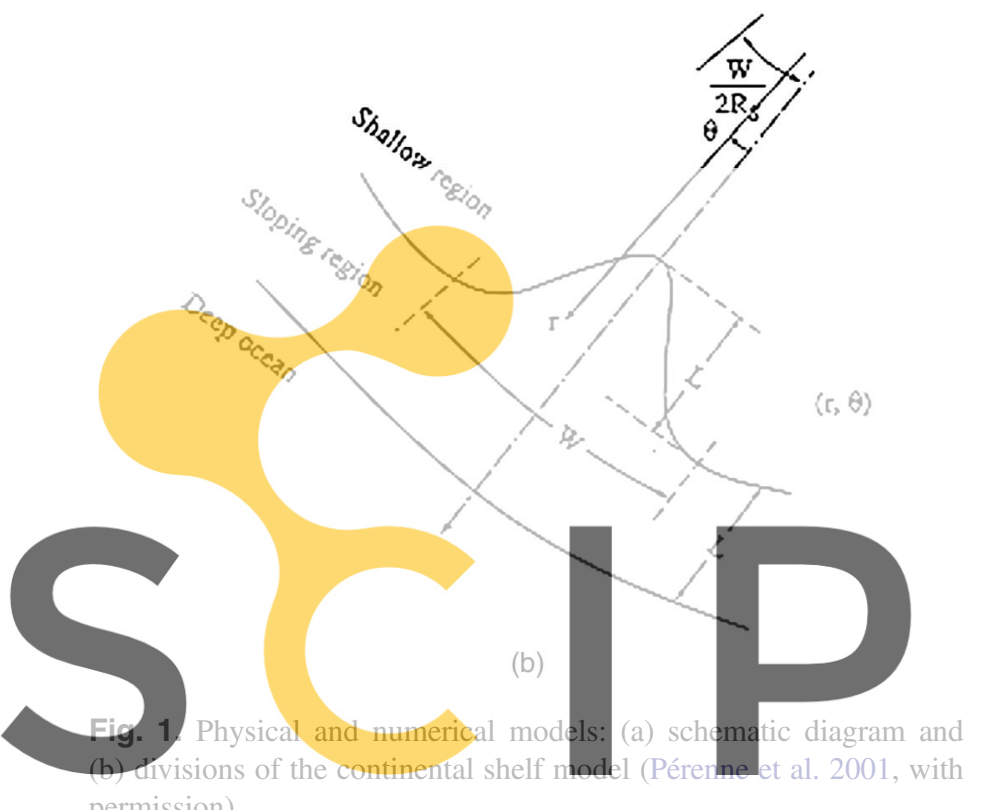

permission)

Register for free at https//www.scipedia.com to Table 1. Dimensional Values for the Numerical Model

\begin{tabular}{lc}
\hline Parameter & Value \\
\hline$R_{C}$ (radius of the coast) & $35 \mathrm{~cm}$ \\
$R_{S}$ (radius of the shelf-break) & $55 \mathrm{~cm}$ \\
$R_{T}$ (radius of the test tank) & $90 \mathrm{~cm}$ \\
$h_{s}$ (depth over the shelf) & $2.5 \mathrm{~cm}$ \\
$h_{D}$ (maximum depth) & $12.5 \mathrm{~cm}$ \\
$W$ (width of the canyon) & $20 \mathrm{~cm}$ \\
$L$ (length of the canyon) & $15 \mathrm{~cm}$ \\
$f$ (Coriolis parameter) & $0.5 \mathrm{~s}^{-1}$ \\
$\omega_{0}$ (forcing frequency) & $0.26 \mathrm{~s}^{-1}$ \\
$k_{h}$ (horizontal coefficient of diffusivity) & $1.5 \mathrm{~m}^{2} \mathrm{~s}^{-1}$ \\
$K_{v}$ (vertical coefficient of diffusivity) & $0.1 \mathrm{~m}^{2} \mathrm{~s}^{-1}$ \\
$U o$ (alongshore velocity forced at the shelf break) & $1.0 \mathrm{~cm} \mathrm{~s}^{-1}$ \\
$R_{o t}$ (temporary Rossby number) & 0.52 \\
\hline
\end{tabular}

\section{Computational Mesh and Parameters}

Given the complicated geometry of the study domain, the elemental partitioning was performed by using two different spatial discretization approaches. Initially, to compare the results with the studies of Perénne et al. (2001), the volume domain was discretized by using hexahedral elements in which the meshing was simplified by restricting it to a structured discretization (i.e., the number of

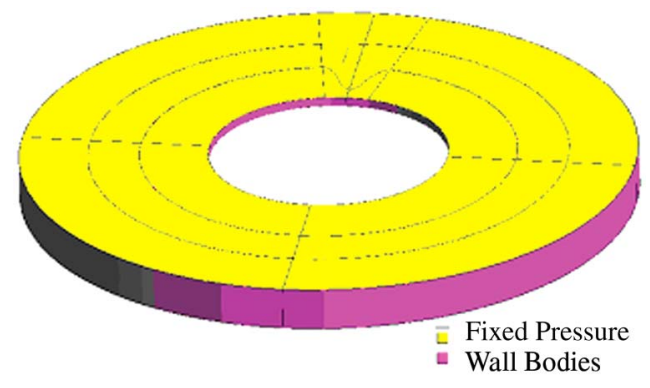

Fig. 2. Boundary conditions of the problem

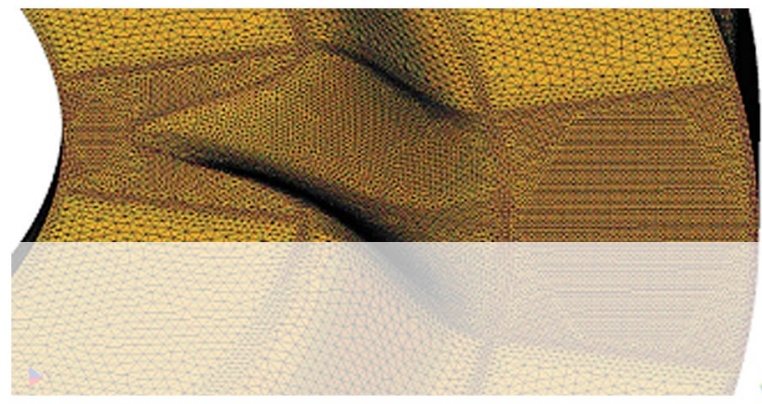

(a)

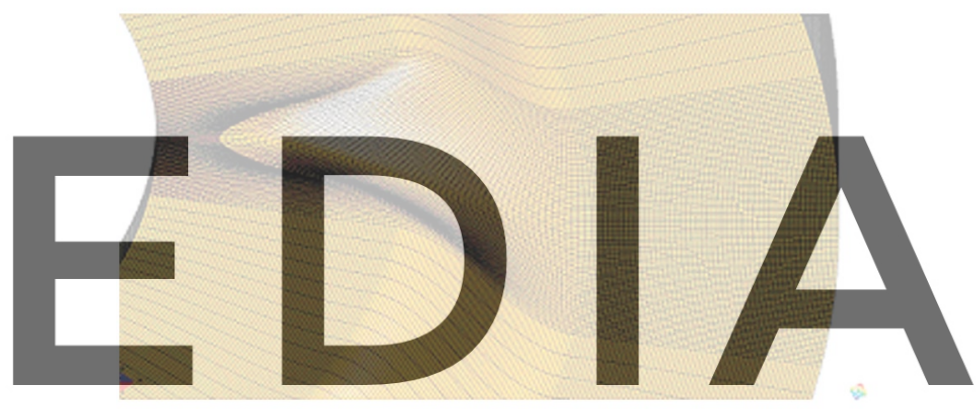

(b)

\section{doyyngload the version without the watermark tured mesh}

vertical elements does not vary horizontally). The generated structured mesh has 166,980 nodes and 192,500 hexahedral elements.

The first computational mesh represented the domain of study well but was not optimized for the problem. Therefore, an unstructured mesh was generated that allows control of the size of the elements in the zone of interest. The resulting mesh has 2,323,547 tetrahedral elements with 395,219 nodes. In both cases, a Dirichlet boundary condition (Fig. 2) was imposed on the sides and bottom of the domain and a Neumann condition with null stress was imposed on the free surface.

Two types of spatial discretizations have been presented, and to discover which of the two types of mesh is more advantageous in terms of representing processes of interest, a new structured mesh was generated in which the characteristic length of the elements in the canyon zone approximates the size of the elements in the unstructured mesh. Fig. 3 shows a comparison of the canyon zone discretized using the two types of mesh generation.

\section{Experimental Results}

This case study analyzes the temporal development of a horizontal velocity field in the canyon zone. The data obtained in the present experiments were the phase-average flow and the residual current at 

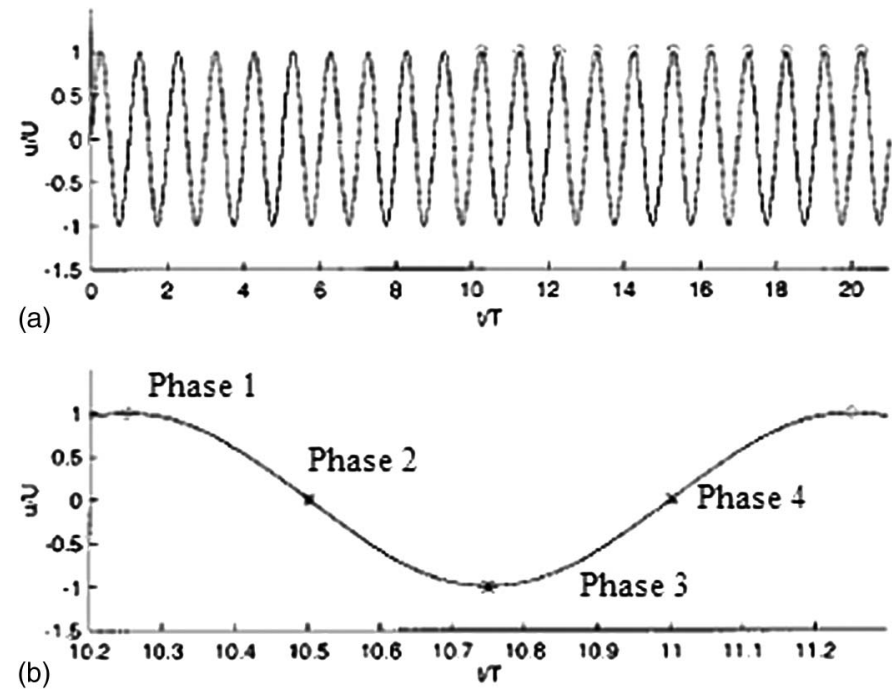

Fig. 1. Temporal averaging of the instantaneous velocity: (a) forcing sequence of the velocity that would be forced at the shelf break in the absence of a canyon and (b) definition of the four phases considered in the study (Pérenne et al. 2001, with permission)

\section{(1)}

the shelf break level $(z=-2.5 \mathrm{~cm})$. Fig. 4 defines the different kinds of temporal averages performed during the processing of the velocity data. The temporal averaging of the velocity field

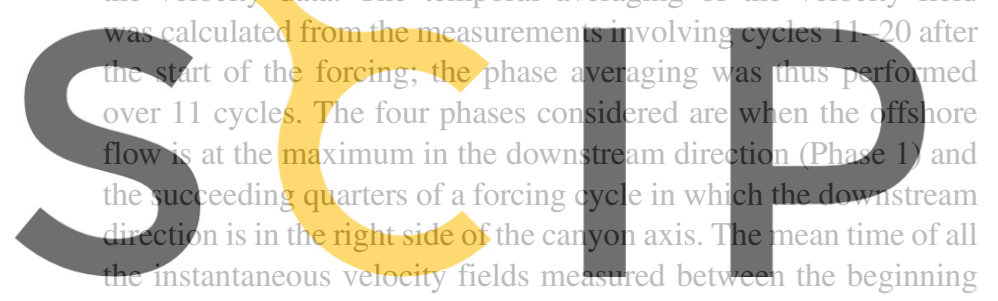

\section{Register for free at https//www.scipedia.com to download the version without the watermark}
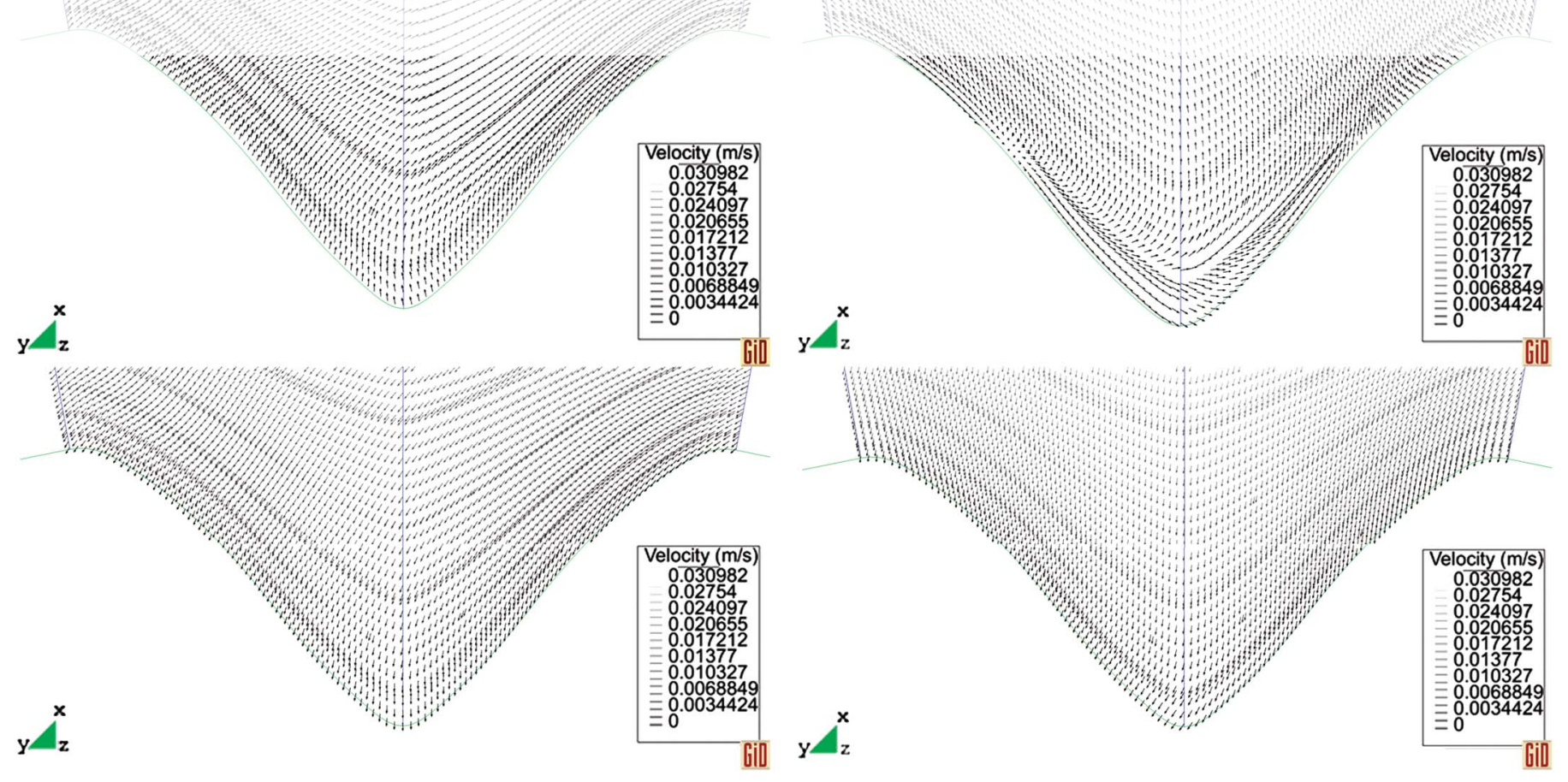

Fig. 5. Numerical model phase-averaged velocity fields obtained at $z=-5 \mathrm{~cm}$ (structured mesh) for the four phases indicated in Fig. 4 of the 11 th cycle and the end of the 20th cycle is the experimental

Two situations involving changes in the fluid density were considered to illustrate the effect of submarine canyons on coastal current circulation. The first case involves a homogeneous fluid density and the second considers a stratified fluid condition. Each of these cases was described by the horizontal velocity at three levels: mid-depth on the shelf, $z_{1}=-h_{S} / 2$; shelf break, $z_{2}=-h_{S}$; and below the shelf break, $z_{3}=h_{S}-\left(h_{D}-h_{S}\right) / 4$.

The experiments were performed with $T=24 \mathrm{~s}$ as the oscillation period computed by using a temporal Rossby number defined as

$$
R o_{t}=\frac{2 \pi}{T f}
$$

where $f=$ Coriolis parameter; and $R o_{t}=$ temporal Rossby number. The time interval used for the simulation in all cases is $\Delta t=1 \mathrm{~s}$ with 504 time steps. A small region surrounding the canyon is used to present the simulation results.

\section{Homogenous Fluid Case}

The first test case, using a homogeneous fluid with a density of $1,000 \mathrm{~kg} / \mathrm{m}^{3}$, was the standard scenario for the flow pattern of the four phases defined in Fig. 4. Phase 1 exhibits the maximum rightward pattern, whereas phase 3 represents the maximum leftward flow phase. Phases 2 and 4 are for cases in which the backresidual velocity field.

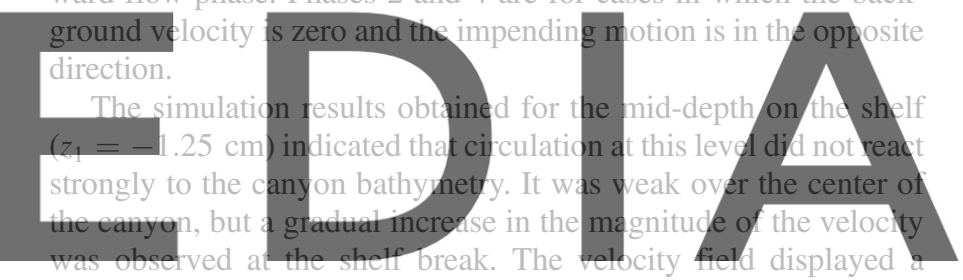




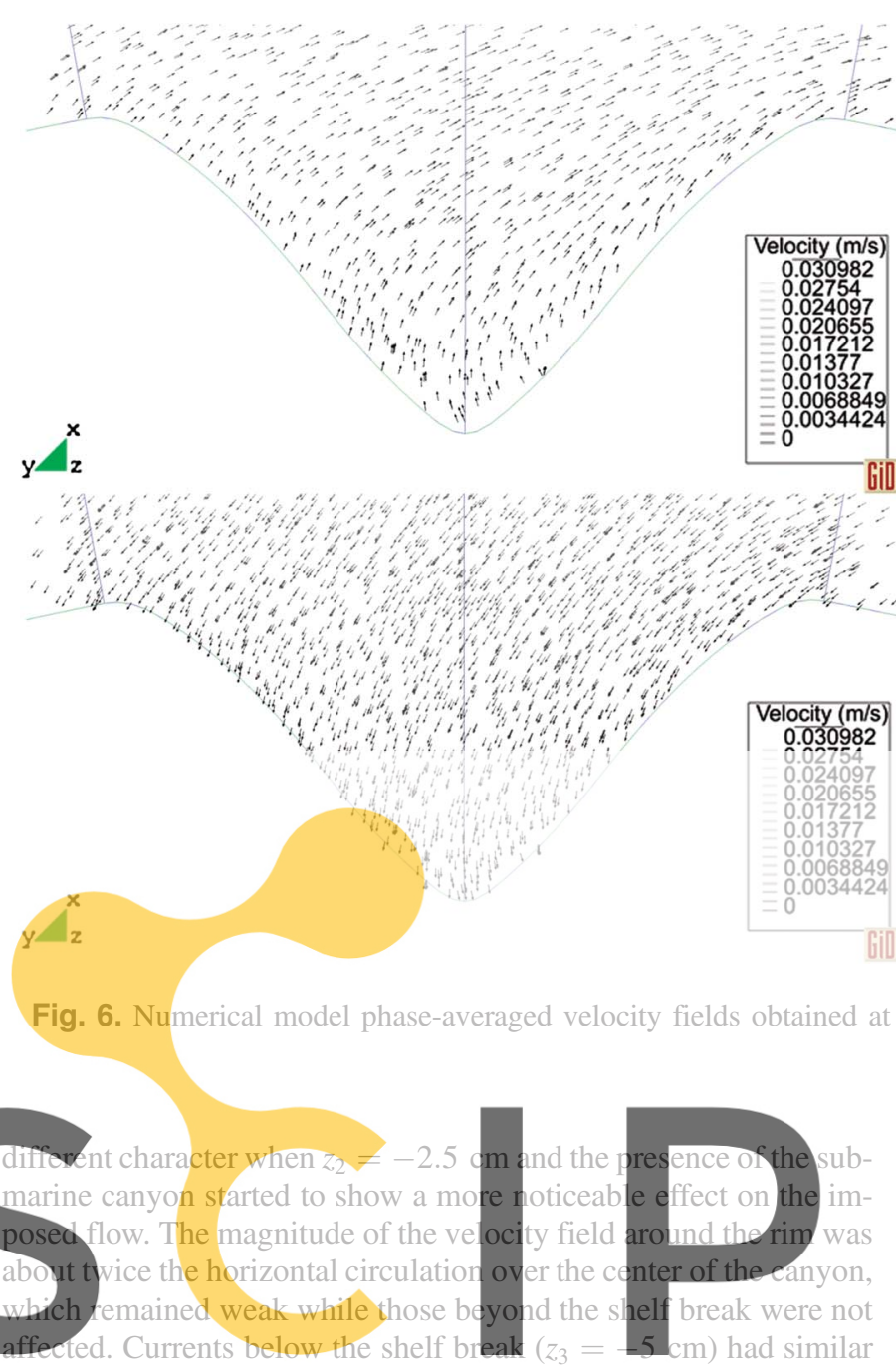

characteristics as those above, with the current around the rim

Registerof than those within the center of the canyon (Figs. 5 and 6 )

mesh generation had similar magnitudes, there were differences in the details; for instance, the results obtained from the unstructured mesh presented a clearer resolution of the ongoing process.

\section{Stratified Fluid Case}

The second case was a repeat of the previous, except that stable fluid stratification was now considered. The profile of density distribution corresponds to the value of the typical Brunt-Väisälä frequency $N=2.5 \mathrm{~s}^{-1}$ defined by the following equation (Dyke 2007):

$$
N^{2}=-\frac{g}{\rho} \frac{\partial \rho}{\partial z}
$$

where $g=$ local acceleration due to gravity; $\rho=$ fluid density; and $z=$ geometric depth.

To evaluate the performance of Tdyn, the simulation results were compared with the outputs of the laboratory experiments presented by Pérenne et al. (2001). The numerical grid used by Perénne et al. has 250,000 nodes.

Fig. 7 shows the phase-averaged velocity fields obtained from the laboratory experiments, whereas Fig. 8 illustrates the numerical results from Tdyn. A good agreement in the direction of the numerical results and the laboratory measurement was noticed in phases 1 and 3 in which both results showed the maximum

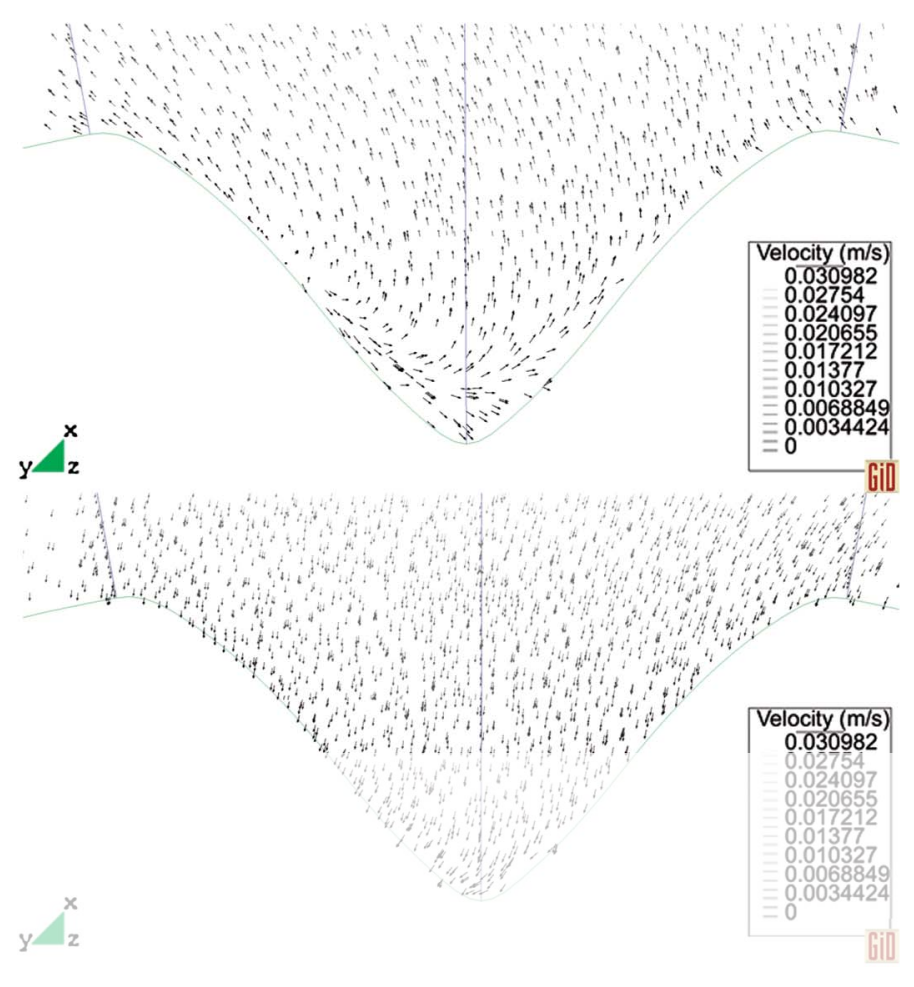

$-5 \mathrm{~cm}$ (unstructured mesh) for the four phases indicated in Fig. 4

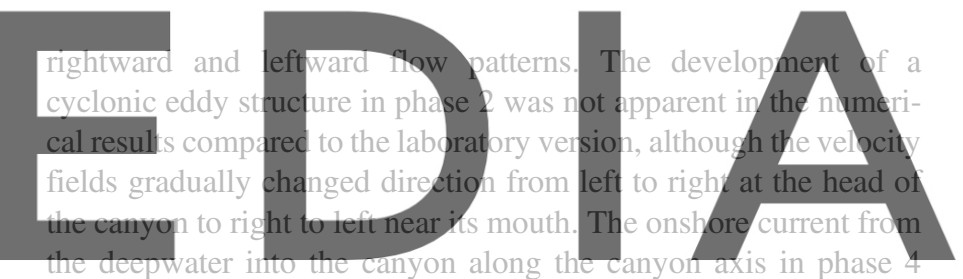

was more evident in the numerical model than its laboratory

downtwatd the version without the watermark and the laboratory measurements are given in Fig. 9. The numerical
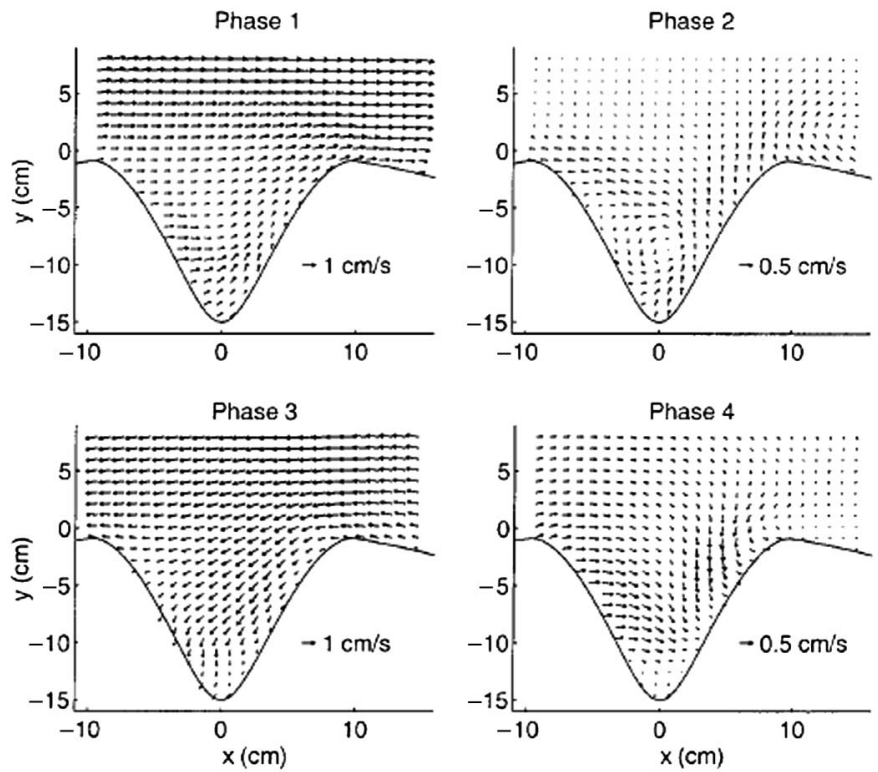

Fig. 7. Laboratory model phase-averaged velocity fields at $z=-2.5 \mathrm{~cm}$ (Pérenne et al. 2001, with permission) 


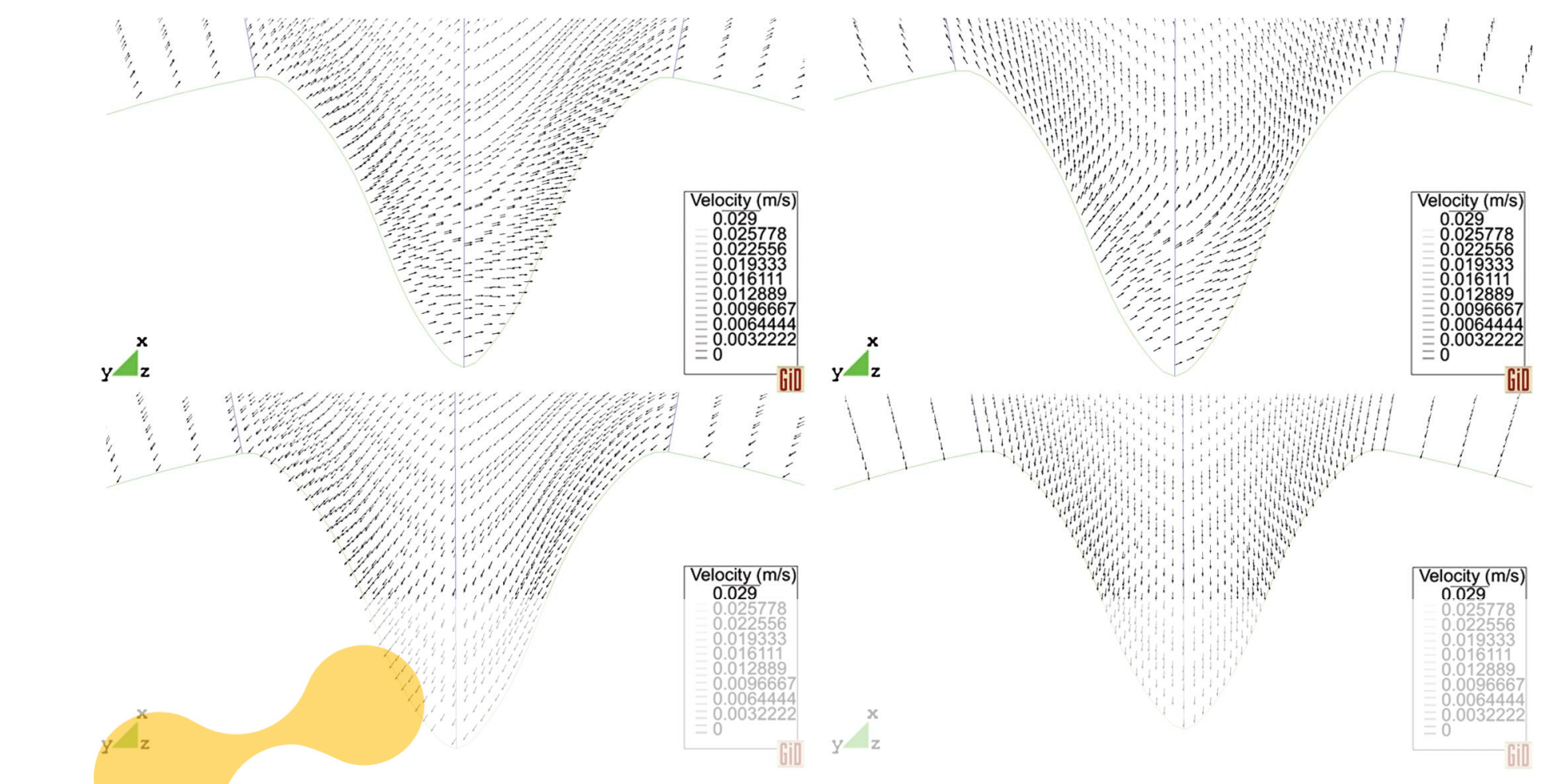

Fig. 8. Numerical model phase-averaged velocity fields at $z=-2.5 \mathrm{~cm}$

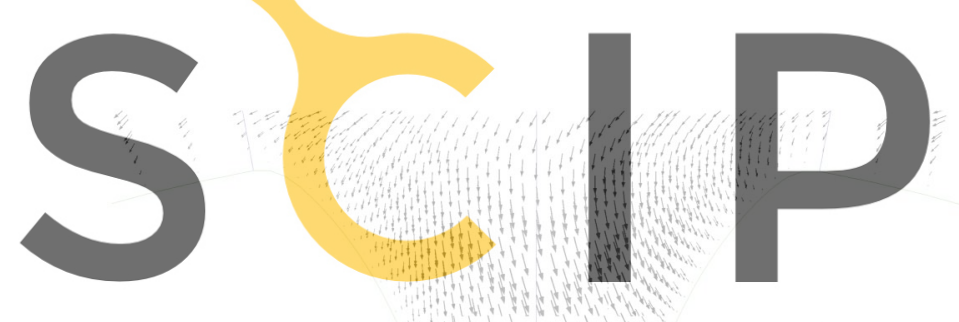

Register for free at https/yww.scipedia.dom y $\mathbf{z}$

(a)

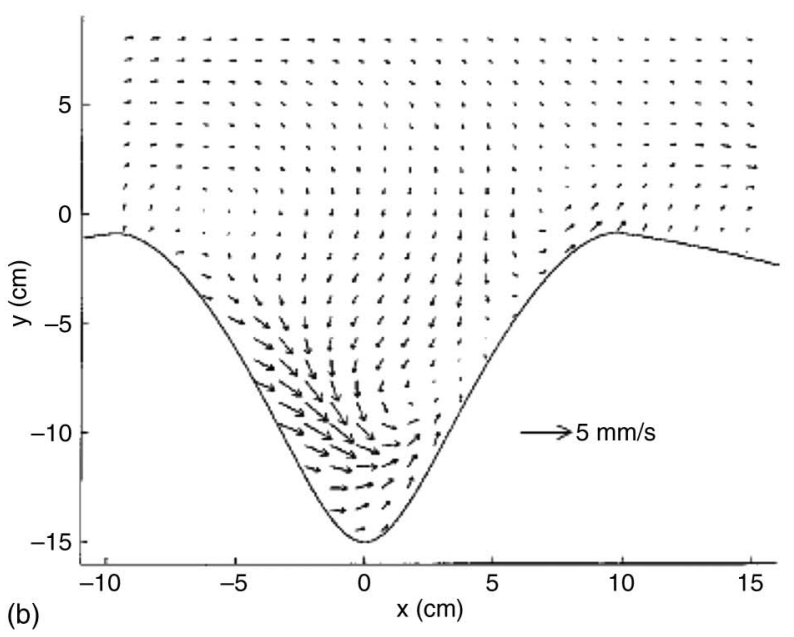

Fig. 9. Comparison of residual velocity fields at $z=-2.5 \mathrm{~cm}$ : (a) numerical model and (b) laboratory model (Pérenne et al. 2001, with permission)

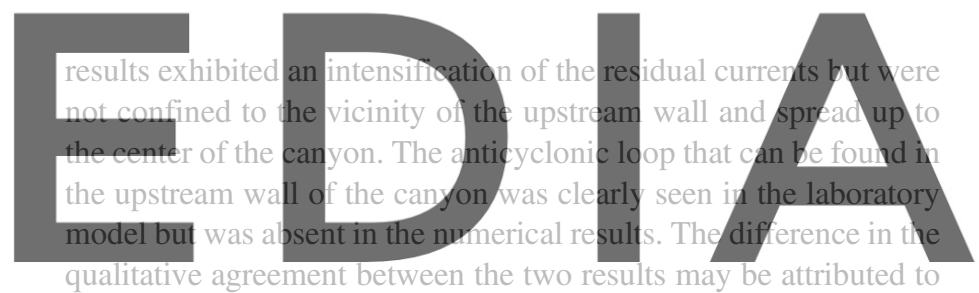

the different set of values for the vertical $\left(0.1 \mathrm{~cm}^{2} \mathrm{~s}^{-1}\right)$ and horidownal oad the verssion twithiout thenvate rimark numerical model, which was because of computational stability constraints,

Similar to the nonstratified simulations, model runs of the stratified situations using the structured and unstructured grids were performed. As mentioned previously, the second structured mesh [Fig. 3(b)] was generated with the characteristic length of the elements in the canyon zone similar in size to the elements in the same location in the unstructured mesh [Fig. 3(a)].

Fig. 10 shows phase 2 of the phase-averaged velocity fields at depths $z_{2}=-2.5 \mathrm{~cm}$ and $z_{3}=-5 \mathrm{~cm}$. The general flow pattern was similar to the previous nonstratified case and the numerical results showed that the horizontal circulation in the center of the canyon was weak. A gradual intensification of the velocity fields was noted near the mouth of the canyon, but it did not move deeper inside the canyon. The circulation below the shelf, $z_{3}=-5 \mathrm{~cm}$, showed similar characteristics as that above the shelf, but the presence of a cyclonic eddy structure was visible in the numerical results obtained from the unstructured mesh.

The difference between the stratified fluid condition and the previous case in which the fluid density was homogeneous can be better visualized in the magnitude of the velocity fields. Observation of the numerical results showed similarity in the general flow behavior; however, the increase in the fluid density reduced the magnitude of the velocity fields (cf. maximum value for homogeneous and stratified fluid condition) in the canyon zone (Fig. 11). 

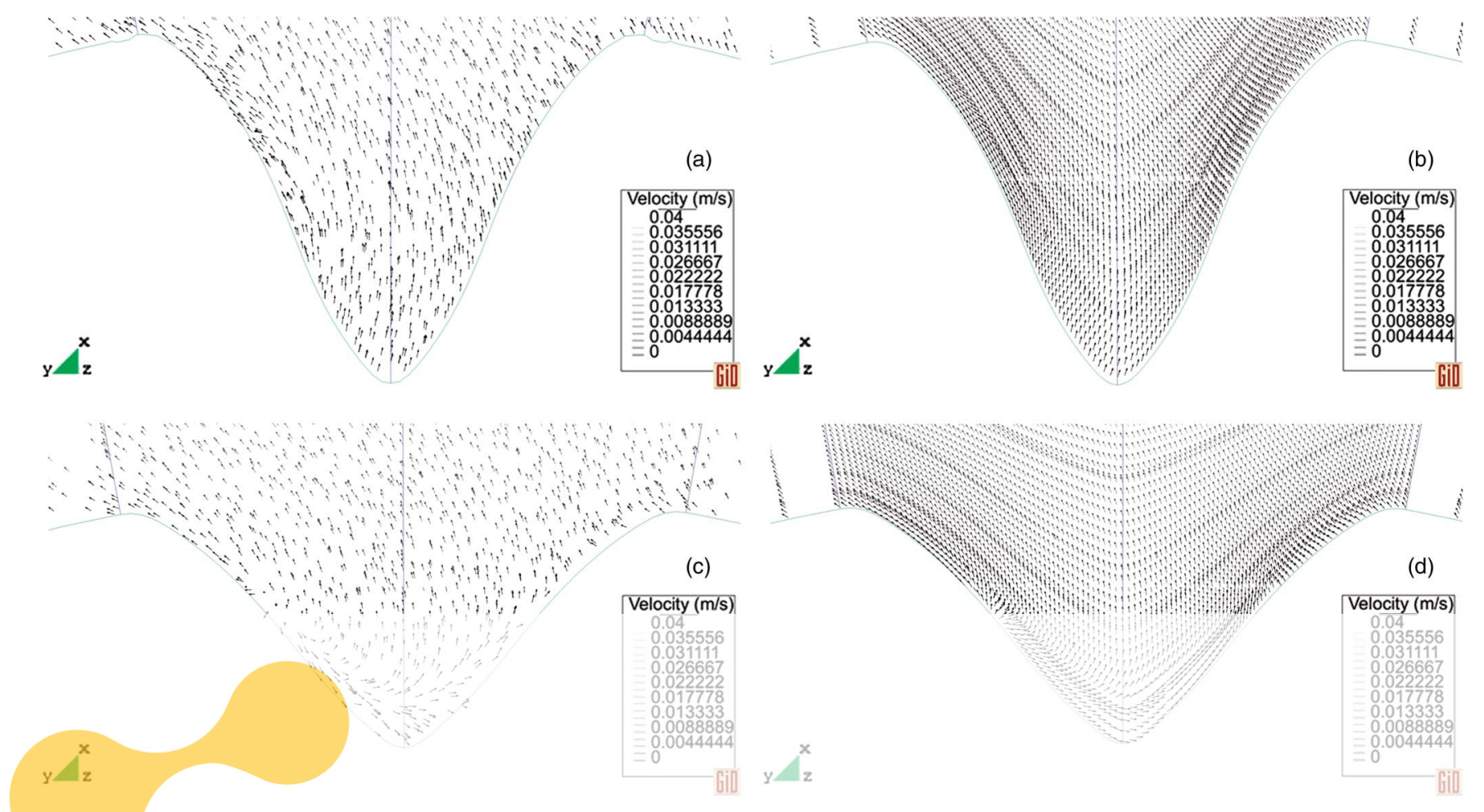

Fig. 10. Comparison of phase-averaged velocity fields (phase 2) (a) unstructured and (b) structured mesh at $z=-2.5 \mathrm{~cm}$; (c) unstructured and (d) structured mesh at $z=-5 \mathrm{~cm}$
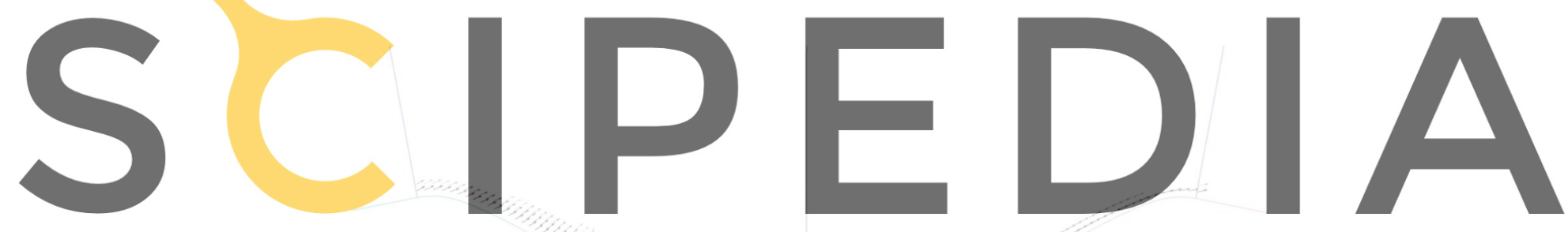

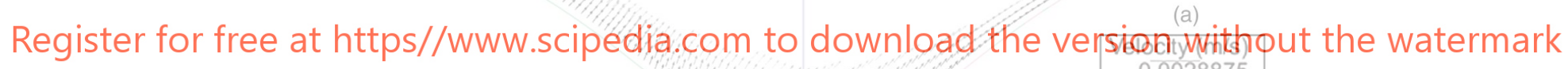

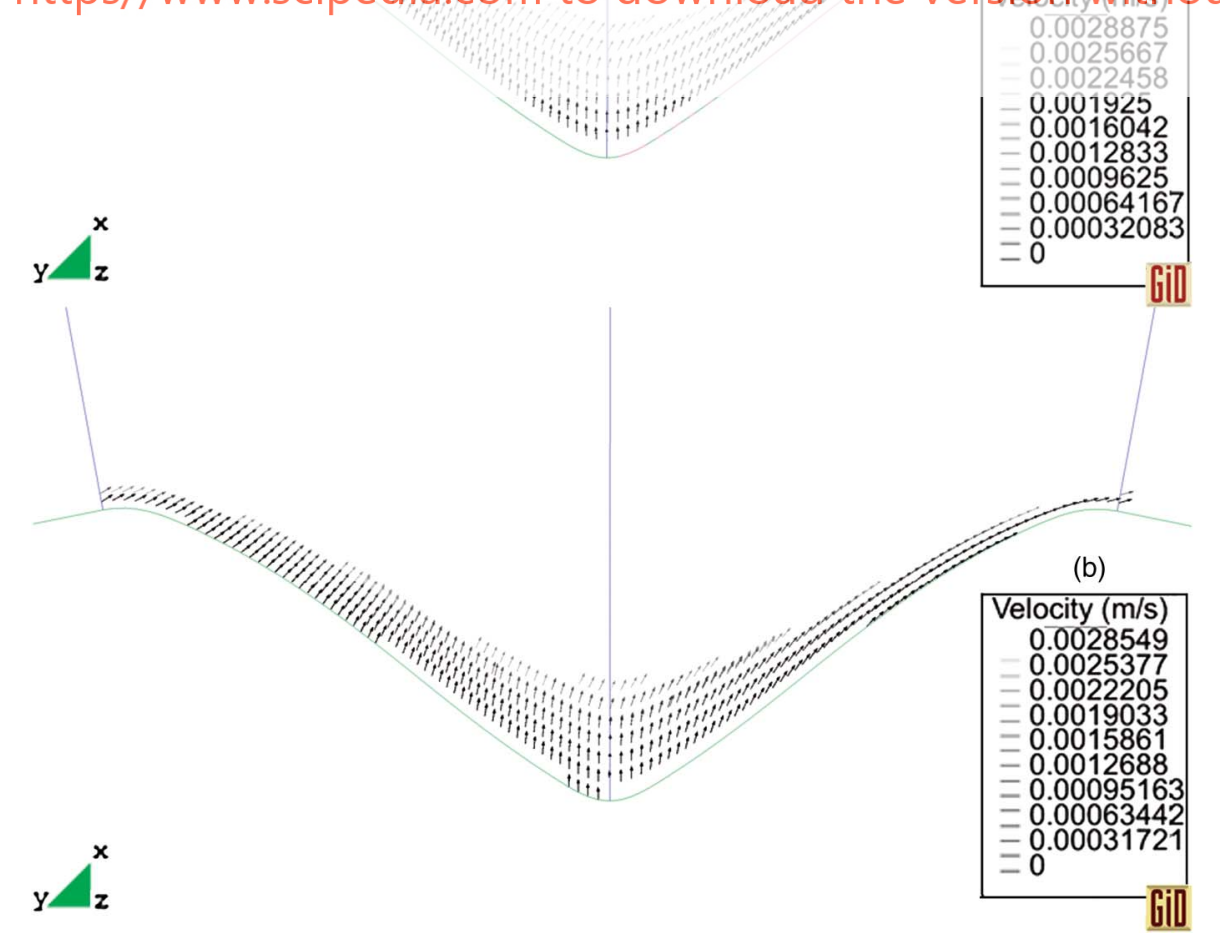

Fig. 11. Comparison of (a) homogeneous and (b) stratified fluid condition phase-averaged velocity fields (phase 1$)$ at $z=-7.5 \mathrm{~cm}$ 


\section{Conclusion}

Several numerical experiments have been performed to simulate currents near and within a model of a submarine canyon located on a continuous shelf, shelf break, and continental slope topography. The model setup was taken from the laboratory experiments of Boyer et al. (2000) and the numerical model simulations were on a physical model scale. The dynamic setting involved an oscillatory background flow produced by modulating the rotation rate of the turntable. On the basis of model results, some issues regarding coastal flow near a submarine canyon were analyzed.

The results of this study showed that in the upper layers, the influence of canyon topography on current circulation was minimal. In deeper layers, the presence of submarine canyons changed the direction of the current circulation.

The effect of fluid density also contributed to limit the influence of the canyon on the overlying flow. The magnitude of the velocity fields in stratified conditions differed from their homogeneous counterparts because vertical motions were diminished in the former. This effect can be seen in the difference in the value of numerical results obtained from the homogeneous and stratified fluid conditions. The magnitude of the velocity fields obtained in the homogenous fluid condition was slightly stronger (1.15\%) than the results obtained from stratified condition. The numerical results were in consonance with the observation that as the stratification increases, the effect of the canyon decreases (Klinck 1996).

The computation of phase-averaged and residual velocity fields generally agreed with the previous studies done by Pérenne et al, (2001. This suggests that the numerical model Tdyn can be wsed in a comprehensive canyon-flow analy tion include a real life application of coasta flow circulation in Blane Finglly, the use of unstructured $m$ grids.

\section{Register for free at https//www.scipedia.com to}

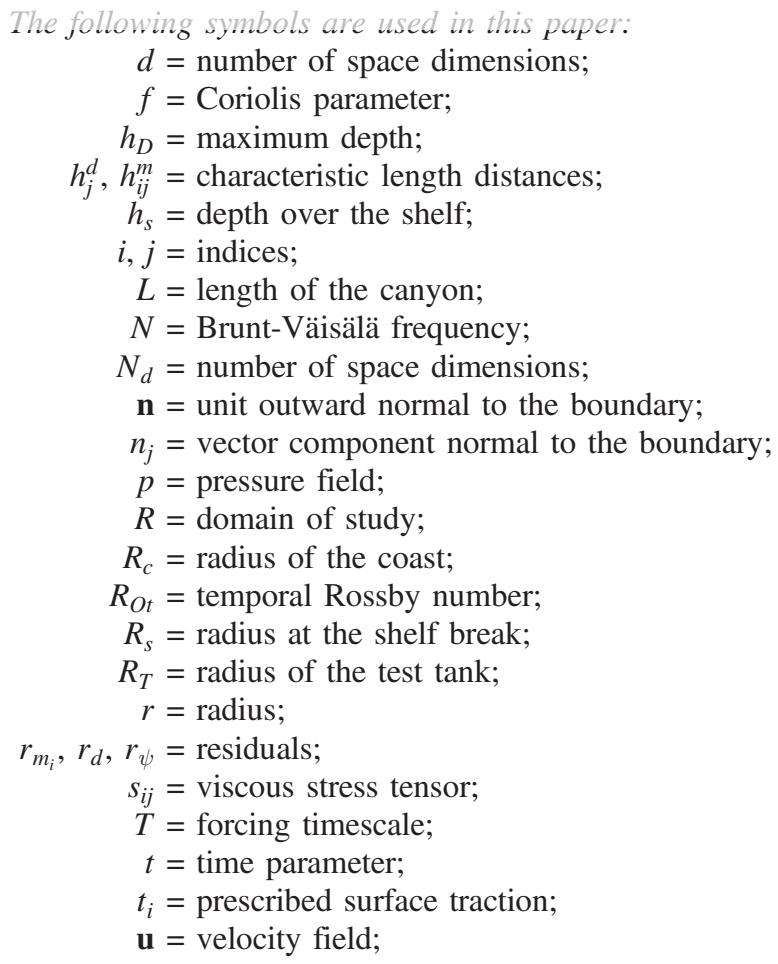

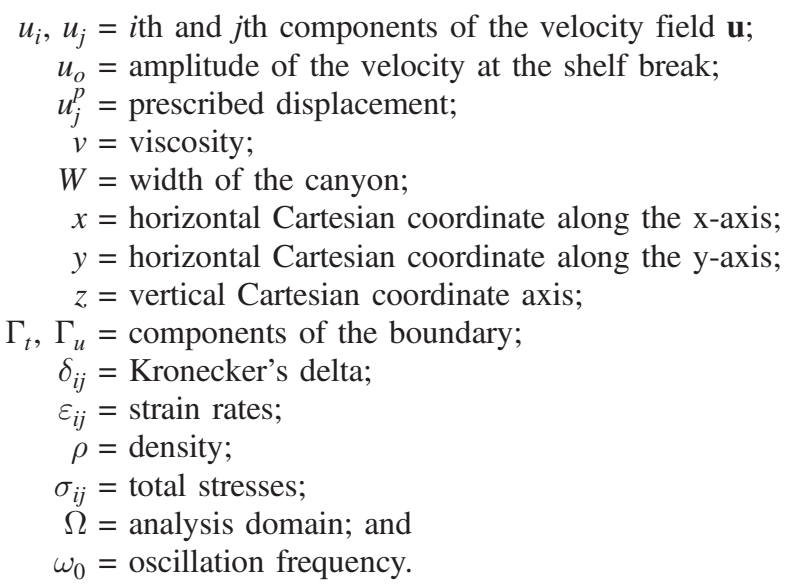

\section{References}

Allen, S. E. (1996). "Topographically generated, subinertial flows within a finite length canyon." J. Phys. Oceanogr., 26(8), 1608-1632.

Bosley, K. L., et al. (2004). "Biological and physical processes in and around Astoria submarine Canyon, Oregon, USA." J. Mar. Syst., 50(1-2), 21-37

Boyer, D. L., Zhang, X., and Pérenne, N. (2000). "Laboratory observations of rotating, stratified flow in the vicinity of a submarine canyon." Dyn. Atmos. Oceans, 31(1-4), 47-72.

Durrieu de Madron, X. (1994). "Hydrographic and nepheloid structures in the Grand Rhône canyon." Cont. Shelf Res., 14(5), 457-477.

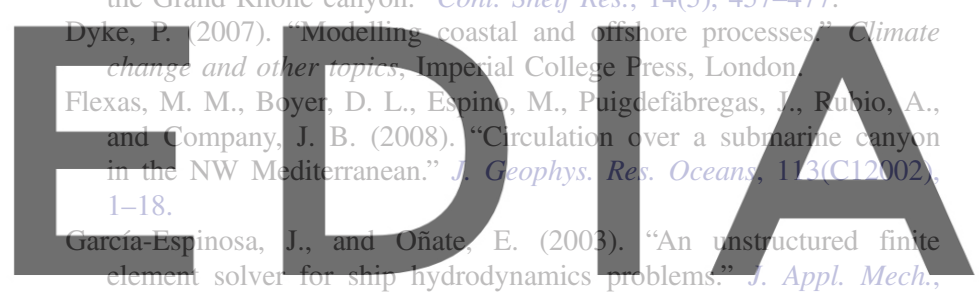
$70(1), 18-26$

García Espingsa J., Valls, A,.and Onate E (2008) "ODDLS: A new unflow problems." Int. J. Numer. Methods Eng., 76(9), 1297-1327.

Gili, J. M., et al. (2000). "A multidisciplinary approach to the understanding of hydromedusan populations inhabiting Mediterranean submarine canyons." Deep Sea Res. Part I, 47(8), 1513-1533.

Haidvogel, D. B., and Beckman, A. (1995). "Wind driven residual currents over a coastal canyon." Proc. Hawaiian Winter Workshop, P. Müller, and D. Henderson, eds., Univ. of Hawaii, Manoa, HI, 219-224.

Hickey, B. M. (1995). "Coastal submarine canyons." Proc. Hawaiian Winter Workshop, P. Müller, and D. Henderson, eds., Univ. of Hawaii, Manoa, HI, 95-110.

Hickey, B. M. (1997). "The response of a steep-sided, narrow canyon to time variable wind forcing." J. Phys. Oceanogr., 27(5), 697-726.

Hurlburt, H. E. (1974). "The influence of coastline geometry and bottom topography on the eastern ocean circulation." Ph.D. thesis, Florida State Univ., Tallahassee, FL.

Huthnance, J. M. (1995). "Circulation, exchange and water masses at the ocean margin: The role of physical processes at the shelf edge." Prog. Oceanogr., 35(4), 353-431.

Klinck, J. M. (1988). "The influence of a narrow traverse canyon on initially geostrophic flow." J. Geophys. Res., 93(C1), 509-515.

Klinck, J. M. (1996). "Circulation near submarine canyons: A modeling study." J. Geophys. Res., 101(C1), 1211-1223.

Oñate, E. (1998). "Derivation of stabilized equations for advectivediffusive transport and fluid flow problems." Comput. Meth. Appl. Mech. Engng., 151(1-2), 233-267.

Oñate, E., and García-Espinosa, J. (2001). "A finite element method for fluid-structure interaction with surface waves using a finite element calculus formulation." Comput. Meth. Appl. Mech. Engng., 191(6-7), $635-660$. 
Oñate, E., García-Espinosa, J., and Idelsohn, S. (2004). "Ship hydrodynamics." Encyclopedia of computational mechanics, E. Stein, R. De Borst, and T. J. R. Hughes, eds., Wiley.

Oñate, E., García-Espinosa, J., Idelsohn, S., and del Pin, F. (2006). "Finite calculus formulation for finite element analysis of incompressible flow, Eulerian, ALE and Lagrangian approaches." Comput. Meth. Appl. Mech. Engng., 195(23-24), 3001-3037.

Peffley, M. B., and O’Brien, J. J. (1976). "A three-dimensional simulation of coastal upwelling off Oregon." J. Physics Oceanogr., 6(2), 164-180.
Pérenne, N., Haidvogel, D. B., and Boyer, D. L. (2001). "Laboratorynumerical model comparisons of flow over a coastal canyon." J. Atmos. Ocean. Technol., 18(2), 235-255.

Sardà, F., Cartes, J. E., and Company, J. B. (1994). "Spatio-temporal variations in megabenthos abundance on three different habitats of the Catalan deep sea (western Mediterranean)." Mar. Biol., 120(2), 211-219.

Tdyn [Computer software]. Compass Ingeniería y Sistemas, Barcelona, Spain, 〈http://www.compassis.com/en/productos/tdyn/index.html〉.
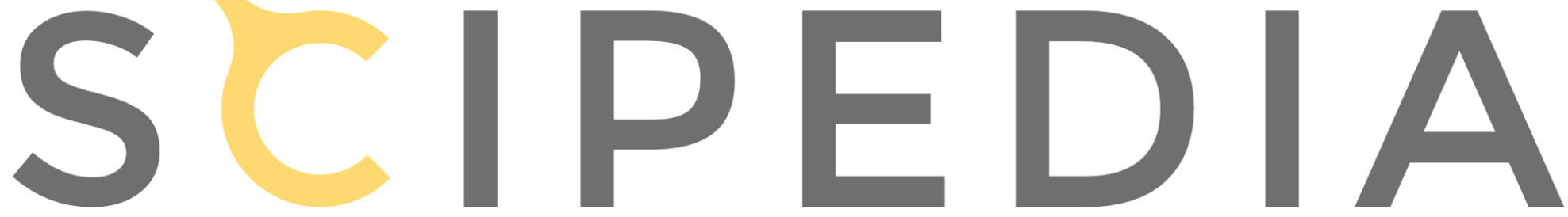

Register for free at https//www.scipedia.com to download the version without the watermark 